\title{
Prognostic value of long non-coding RNA BLACAT1 in patients with papillary thyroid carcinoma
}

\author{
Denghui Liao ${ }^{1}$, Gang Lv', Ting Wang ${ }^{2}$, Jie Min², Yadong Wang ${ }^{2}$ and Shengchun Liu ${ }^{{ }^{*}}$ (D)
}

\begin{abstract}
Background: Long noncoding RNAs (IncRNAs) have been reported to have potential diagnostic and prognostic values for numerous cancers. However, the plasma expression of IncRNA BLACAT1 and its clinical value in patients with papillary thyroid cancer (PTC) remain unknown.

Methods: The expression profile of BLACAT1 in 87 PTC patients (case group) and 36 patients with nodular goiter (control group) were investigated by qRT-PCR. The Kaplan-Meier method was used for RFS curves, and the univariate survival differences were analyzed by the log-rank test.

Results: BLACAT1 expression was downregulated in the plasma of case group compared with control group $(\mathrm{P}=0.003)$. We also found that low plasma BLACAT1 expression was correlated with lymph node metastasis (LNM) $(\mathrm{P}<0.001)$. Multivariate analysis showed that BLACAT1 was an independent risk factor for lymph node metastasis and gender $(P<0.05)$. The area under the ROC curve for BLACAT1 was 0.825 in LNM prediction $(P<0.001)$.
\end{abstract}

Conclusion: The present study demonstrated that BLACAT1 could act as a possible suppressor gene in PTC and may serve as a potential biomarker for prognosis prediction of PTC.

Keywords: Long noncoding RNAs (IncRNAs), Papillary thyroid cancer (PTC), Metastasis, Survival

\section{Background}

Thyroid carcinoma is the most common endocrine neoplasm worldwide [1]. About 300,000 patients are diagnosed with thyroid carcinoma each year. The median age at the time of diagnosis is 50 years old, and approximately 40,000 people die from thyroid carcinoma. Papillary thyroid carcinoma (PTC) is the most prevalent type of thyroid carcinoma, accounting for $80 \%$ of all thyroid carcinomas [2, 3]. Generally, thyroid carcinomas develop slowly and can be cured by thyroidectomy or radioiodine, even for the thyroid metastatic carcinoma [4]. Most patients with PTC have a good prognosis, but a small fraction of patients develop PTC with dedifferentiation, resulting in aggressive features and poor prognosis [5].

*Correspondence: cmushengchunliu@163.com

1 Department of Endocrinology and Breast Surgery, the First Affiliated Hospital of Chongqing Medical University, Chongqing 400043, China

Full list of author information is available at the end of the article
At present, newly-found target drug combined treatment changes the effectiveness of thyroid cancer with a poor response to radioiodine [6]. BRAF V600E mutation can affect iodine metabolism and decrease the absorption of ${ }^{131}$ I of the thyroid gland through BRAF/MEK/MAPK pathway. Therefore it may become a potential therapy target for PTC [7]. Researchers have found the relationship between some molecules and invasion in thyroid carcinoma currently [8]. However, new biomarkers in blood for predicting the invasiveness of PTC need to be further identified.

Long non-coding RNAs (lncRNAs) are conservative, non-coding RNAs with more than 200 nucleotides in length. Many lncRNAs have biological functions, such as regulating the transcription and translation of protein-coding sequences [9]. LncRNA can regulate the growth and metastasis of tumors by altering the expression of different molecules and affecting chromatin structure, transcriptional activity, mRNA stability, and 
transcription process or translation of mRNA [10]. Over the past 10 years, more and more evidence has shown that lncRNAs play an important role in tumor proliferation and metastasis. For example, lncRNA GAPLINC stimulated SNAI2 as a transcriptional vector combined with PSF and NONO to promote the invasion of colorectal cancer [11]. In thyroid carcinoma tissues, Kim et al. found that 56 lncRNAs were related to thyroid carcinoma, and proved that lymph node metastasis (LNM) of thyroid cancer was closely associated with BRAF V600E mutation and LOC100507661 [12]. BLACAT1, also known as linc-UBC1, locus on human chromosome 1q32.1, has been reported to be upregulated and serve as a negative prognostic factor in many types of cancers [13]. However, the clinical and biological significances of BLACAT1 in PTC are still unclear. The purpose of this study was to evaluate the diagnostic and predicting value of BLACAT1 related to survival and recurrence of PTC patients.

\section{Materials and methods Patients and samples}

A total of 87 cases of PTC enrolled in Chongqing Medical University from January 2011 to June 2013 and 36 patients with nodular goiter (NG) were included in this study. Patients with other tumors, or tumor history, or received chemotherapy and radiotherapy were excluded. $10 \mathrm{ml}$ fasting blood samples of all patients before surgery were collected. Blood samples were placed in the K2-EDTA tubes, and centrifuged at $800 \times g$ for $15 \mathrm{~min}$. Plasma samples were immediately transferred to tubes without ribonuclease/deoxyribonuclease. Then phosphate buffered saline was added to $20 \mu$ l plasma samples with the ratio of 1:4 for spectrophotometric analysis. The samples were with hemolysis and stored at $-80{ }^{\circ} \mathrm{C}$ before use. The diagnosis of PTC or nodular goiter was performed by two pathologists independently. The study was approved by the Clinical Research Ethics Committee of Chongqing Medical University and in accordance with the ethical standards formulated in the Helsinki Declaration and the national regulations. All patients signed informed consent.

\section{qRT-PCR}

Total RNA was isolated from plasma samples with Trizol reagent (Invitrogen Life Technologies Co, Carlsbad, CA, USA) according to the manufacturer's instruction. The quality of RNA samples was evaluated by ultraviolet spectrophotometer (Bio-Rad, Hercules, CA, USA) and the $260 / 280 \mathrm{~nm}$ absorbance ratio of the RNA samples was at 1.8-2.0. Total RNA (500 ng) was then reversetranscribed into cDNA with the first strand cDNA synthesis kit (Takara, Tokyo, Japan). Quantitative real-time
PCR (qRT-PCR) was performed using ViiA 7 real-time PCR System (Applied Biosystems, Foster City, CA, USA). The primer sequences of IncRNA BLACAT1 and $\beta$-actin were designed and synthesized by KangChen Bio-tech (Shanghai, China).

The primer sequences for lncRNA BLACAT1: F 5'-GA CAAAGCACAAGCGAAACAAG- $3^{\prime}$ and $\mathrm{R} 5^{\prime}$-GGACA TCTGATAGCCTGGTGAC- $3^{\prime}$, $\beta$-actin: F $5^{\prime}$-GCGACTT TTGGCGAGGATTG- $3^{\prime}$ and $\mathrm{R} 5^{\prime}$-CCTTCCAGTAACA CGAATCTATT-3'. PCR reaction was as follows: predenaturing $95{ }^{\circ} \mathrm{C} 15 \mathrm{~min}$, denaturing $95{ }^{\circ} \mathrm{C} 15 \mathrm{~s}, 55{ }^{\circ} \mathrm{C}$ $45 \mathrm{~s}, 95^{\circ} \mathrm{C} 10 \mathrm{~s}, 35$ cycles. The gene expression of all the samples was analyzed and the difference between patients and healthy controls was calculated by $2^{-\Delta \Delta C t}$. The experiment was repeated three times. Plasma BLACAT1 high expression and BLACAT1 low expression were divided by the median value.

\section{Statistical analysis}

All statistical analyses were performed with SPSS software (version 21.0, Inc., Chicago, IL, USA). The data were expressed as mean and standard deviation. Comparison between groups was performed using Student t-test or non-paired Mann-Whitney test. The qualitative data were expressed as the number of cases or percentages and assessed by $\chi^{2}$ test. Receiver operating characteristic curves (ROC) were used to assess the value of BLACAT1 to predict lymph node canceration and LNM. Multivariable logistic regression analysis was used and data were expressed with odds ratio (OR) and 95\% confidence interval $(95 \% \mathrm{CI}) . P<0.05$ was regarded as statistically significant.

\section{Results}

Down-regulation of IncRNA BLACAT1 expression in plasma of PTC patients

As compared with the control group, the expression of BLACAT1 in plasma was downregulated in PTC patients $(\mathrm{P}=0.003)$. Multivariable analysis showed that downregulation of BLACAT1 in plasma was an independent risk factor for PTC (Table 1). The diagnostic value of BLACAT1 on nodular goiter and PTC was evaluated by ROC curve. The AUC was 0.864 (95\% CI 0.634-0.821, $\mathrm{P}<0.001)$. The sensitivity and specificity were 89.53 and $86.91 \%$, respectively (Fig. 1).

\section{Correlation between IncRNA BLACAT1 and clinicopathological traits}

To explore the correlation between plasma lncRNA BLACAT1 and clinicopathological traits, PTC patients were assigned into low and high expression groups based on the median expression value of BLACAT1. Our data demonstrated that down-regulation of lncRNA 
Table 1 Association between lymph node metastasis and IncRNA BLACAT1 expression by multivariate analysis

\begin{tabular}{llll}
\hline & \multicolumn{3}{l}{ IncRNABLACAT1 } \\
\cline { 2 - 4 } & OR & $\mathbf{9 5 \% ~ C l}$ & P value \\
\hline PTC diagnosis & 0.887 & $0.833-0.982$ & $0.013^{*}$ \\
Model 1 & & & \\
Lymph node metastasis & & & \\
Model 1 & 0.596 & $0.459-0.805$ & $<0.001^{* *}$ \\
Model 2 & 0.504 & $0.341-0.798$ & $0.005^{*}$ \\
\hline
\end{tabular}

Model 1, adjusted for sex and age. Model 2, adjusted for sex, age, thyroidstimulating hormone pre-operation, tumor size, extra thyroidal extension, multifocality, nodular goiter, and Hashimoto thyroiditis

${ }^{*} \mathrm{P}<005$ and ${ }^{* *} \mathrm{P}<0.001$

BLACAT1 expression was associated with LNM and gender $(P<0.05)$. However, no correlation was found between lncRNA BLACAT1 and extrathyroidal extension, age, tumor size, or advanced TNM stage (Table 2).

\section{Correlation between IncRNA BLACAT1}

and clinicopathological traits of patients with papillary thyroid microcarcinoma (PTMC)

Furthermore, correlations of BLACAT1 and clinicopathological traits of PTMC patients $(\mathrm{n}=62$, tumor volume $<1 \mathrm{~cm}^{3}$ ) were also analyzed. We found significant correlations between BLACAT1 expression and LNM and gender $(P<0.05$, Table 3$)$, but no correlation was found between BLACAT1 and other clinicopathological traits.

\section{Relationship between IncRNA BLACAT1 and LNM}

Expressions of plasma lncRNA BLACAT1 in PTC patients with LNM and without metastasis were compared. Our data showed that PTC patients with LNM had lower plasma BLACAT1 expression $(P=0.002$, Fig. 2). Multivariable analysis showed that down-regulation of BLACAT1 in plasma was associated with LNM (Table 1). The predicting value of BLACAT1 on LNM was evaluated by ROC curve. When the cutoff value was 1.57 , the AUC was 0.825 (95\% CI 0.608-0.827, $\mathrm{P}<0.001$, sensitivity was $77.48 \%$, and specificity was $91.06 \%$ ) (Fig. 2).

\section{Discussion}

PTC usually shows an excellent prognosis after treatment [14]. In recent years, the rapidly rising incidence of PTC has made it a public health problem. With the application of high throughput sequencing technology, more and more studies have begun to focus on the molecular mechanisms of tumors [15]. Although most patients with PTC have a good prognosis after surgical resection combined with radioiodine and levothyroxine treatment, there are still some patients with metastasis and recurrence [16]. The inadequacy of specific diagnostic markers and treatment strategies is the main cause of death for cancer patients [17]. Therefore, to improve the prevention and treatment of PTC, exploration of molecular mechanisms and identification of new diagnostic and prognostic markers are required.

LncRNAs are non-coding RNAs with more than 200 nucleotides in length, which have various biological functions, including cell proliferation, differentiation, and apoptosis $[18,19]$. More and more evidence has demonstrated that lncRNA plays an important role in a variety of cancers [20]. For example, it has been reported that lncRNA BANCR expression is up-regulated in endometrial cancer and it promotes cancer cell proliferation and tumorgenesis [21]. Lnc-GNAT1-1 expression
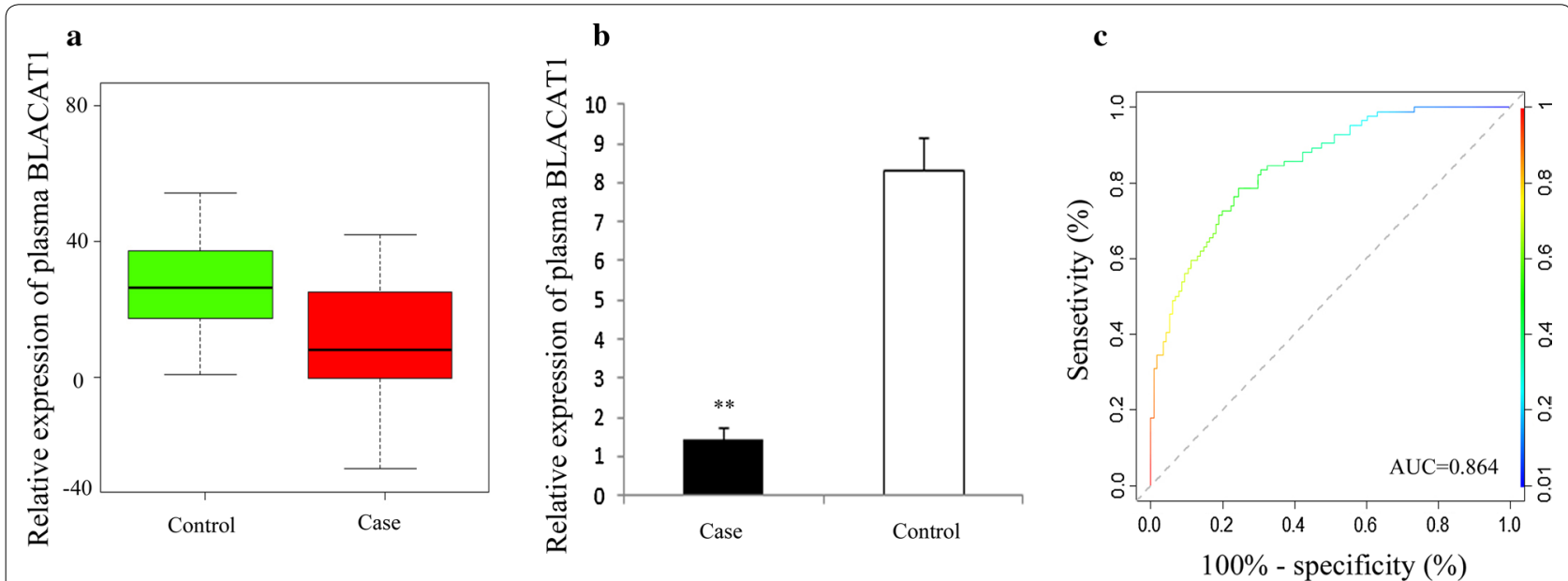

Fig. 1 RT-qRCR and ROC curve analysis of BLACAT1 as a diagnostic marker for PTC. Box plot (a) and histogram (b) of expression of BLACAT1 in plasma of patients with PTC $(n=87)$ and nodular goiter $(n=36)$; $\mathbf{c}$ ROC curve for evaluating the diagnostic value of BLACAT1 (P<0.001) 
Table 2 Association between IncRNA BLACAT1 expression and clinicopathological traits in PTC patients

\begin{tabular}{|c|c|c|c|c|}
\hline \multirow[t]{2}{*}{ Parameters } & \multicolumn{2}{|c|}{ IncRNA BLACAT1 } & \multirow[t]{2}{*}{$x^{2}$} & \multirow[t]{2}{*}{$\mathbf{P}$} \\
\hline & $\begin{array}{l}\text { Low }(\%) \\
(n=44)\end{array}$ & $\begin{array}{l}\text { High (\%) } \\
(n=43)\end{array}$ & & \\
\hline \multicolumn{5}{|l|}{ Gender } \\
\hline Male & $15(34.09)$ & $7(16.28)$ & 5.122 & $0.029^{*}$ \\
\hline Female & $29(65.91)$ & $36(83.72)$ & & \\
\hline \multicolumn{5}{|l|}{ Age (years) } \\
\hline$<45$ & $20(46.94)$ & $25(58.14)$ & 1.825 & 0.317 \\
\hline$\geq 45$ & $24(53.06)$ & $18(41.86)$ & & \\
\hline \multicolumn{5}{|c|}{ Extrathyroidal extension } \\
\hline Positive & $24(54.55)$ & $20(46.51)$ & 0.716 & 0.581 \\
\hline Negative & $20(45.45)$ & $23(53.49)$ & & \\
\hline \multicolumn{5}{|c|}{ Tumor size $(\mathrm{cm})$} \\
\hline$\leq 1$ & $28(63.64)$ & $32(74.42)$ & 1.105 & 0.426 \\
\hline$>1$ & $16(36.36)$ & $11(25.58)$ & & \\
\hline \multicolumn{5}{|l|}{ TNM staging } \\
\hline$|/| \mid$ & $32(72.73)$ & $36(83.72)$ & 3.226 & 0.204 \\
\hline III/IV & $12(27.27)$ & $7(16.28)$ & & \\
\hline \multicolumn{5}{|c|}{ Lymph node metastasis } \\
\hline Positive & $14(31.82)$ & $27(62.79)$ & 9.718 & $0.001^{*}$ \\
\hline Negative & $30(68.18)$ & $16(37.21)$ & & \\
\hline \multicolumn{5}{|c|}{ Nodular goiter } \\
\hline Positive & $25(56.82)$ & $19(44.19)$ & 3.863 & 0.077 \\
\hline Negative & $19(43.18)$ & $24(55.81)$ & & \\
\hline \multicolumn{5}{|l|}{ Multifocality } \\
\hline Positive & $13(29.55)$ & $14(33.56)$ & 0.034 & 1.000 \\
\hline Negative & $31(70.45)$ & $29(67.44)$ & & \\
\hline \multicolumn{5}{|c|}{ Hashimoto thyroiditis } \\
\hline Positive & $7(15.91)$ & $8(18.60)$ & 0.091 & 0.804 \\
\hline Negative & 37 (84.09) & $35(81.40)$ & & \\
\hline
\end{tabular}

* $P<0$ 05, Chi squared test $P$ value

significantly down-regulated in colorectal cancer and it acts as a tumor suppressor through regulating RKIPNF-kB-Snail circuit [22]. In breast cancer, LncRNA ATB regulates ZEB1 and ZNF-217, inducing epithelial mesenchymal transition, which leads to trastuzumab resistance and increased invasion and metastasis [22]. Another study has found that IncRNA MALAT1 promotes the invasion of gastric cancer cells via binding to the core protein complex PRC2 and inhibiting PCDH10 [23]. Moreover, many studies have been suggested that blood lncRNA could be the potential diagnostic markers for tumors [24, 25]. It has been shown that the expression of lncRNA H19 was abnormal in the blood of patients with gastric cancer [26]. A previous study has been reported that up-regulation of lncRNA BLACAT1 expression in bladder cancer, gastric cancer and colorectal cancer is a
Table 3 Correlation between IncRNA BLACAT1 and clinicopathological traits in all patients with PTMC

\begin{tabular}{|c|c|c|c|c|}
\hline \multirow[t]{3}{*}{ Parameters } & \multicolumn{2}{|c|}{ IncRNA BLACAT1 } & \multirow[t]{3}{*}{$x^{2}$} & \multirow[t]{3}{*}{$P$} \\
\hline & Low (\%) & High (\%) & & \\
\hline & $(n=31)$ & $(n=31)$ & & \\
\hline \multicolumn{5}{|l|}{ Sex } \\
\hline Male & $11(35.48)$ & $6(19.35)$ & \multirow[t]{2}{*}{5.823} & \multirow[t]{2}{*}{$0.017^{*}$} \\
\hline Female & $20(64.52)$ & $25(80.65)$ & & \\
\hline \multicolumn{5}{|l|}{ Age (years) } \\
\hline$<45$ & $12(38.71)$ & $14(45.16)$ & \multirow[t]{2}{*}{0.000} & \multirow[t]{2}{*}{1.000} \\
\hline$\geq 45$ & $19(61.29)$ & $17(54.84)$ & & \\
\hline \multicolumn{5}{|c|}{ Extrathyroidal extension } \\
\hline Positive & $9(29.03)$ & $16(51.61)$ & \multirow[t]{2}{*}{2.013} & \multirow[t]{2}{*}{0.364} \\
\hline Negative & $22(70.97)$ & 15 (48.39) & & \\
\hline \multicolumn{5}{|l|}{ TNM staging } \\
\hline$|/| \mid$ & $5(16.13)$ & $4(12.90)$ & \multirow[t]{2}{*}{0.516} & \multirow[t]{2}{*}{0.849} \\
\hline III/IV & $26(83.87)$ & $27(87.10)$ & & \\
\hline \multicolumn{5}{|c|}{ Lymph node metastasis } \\
\hline Positive & $20(64.52)$ & $10(32.26)$ & \multirow[t]{2}{*}{9.014} & \multirow[t]{2}{*}{$0.005^{*}$} \\
\hline Negative & $11(35.48)$ & $21(67.74)$ & & \\
\hline \multicolumn{5}{|l|}{ Multifocality } \\
\hline Positive & $12(38.71)$ & $10(32.26)$ & \multirow[t]{2}{*}{0.323} & \multirow[t]{2}{*}{0.9240} \\
\hline Negative & $19(61.29)$ & $21(67.74)$ & & \\
\hline \multicolumn{5}{|c|}{ Hashimoto thyroiditis } \\
\hline Positive & $8(25.81)$ & $9(29.03)$ & \multirow[t]{2}{*}{0.092} & \multirow[t]{2}{*}{1.000} \\
\hline Negative & $23(74.19)$ & $22(70.97)$ & & \\
\hline \multicolumn{5}{|c|}{ Nodular goiter } \\
\hline Positive & $16(51.61)$ & $13(41.94)$ & \multirow[t]{2}{*}{0.841} & \multirow[t]{2}{*}{0.603} \\
\hline Negative & 15 (48.39) & $18(58.06)$ & & \\
\hline
\end{tabular}

${ }^{*} \mathrm{P}<0$ 05, Chi squared test $\mathrm{P}$ value

poor prognostic factor [13]. However, the plasma expression of lncRNA BLACAT1 in PTC patients and its diagnostic and prognostic values have not been completely elucidated.

In this study, we found that the plasma expression of IncRNA BLACAT1 was significantly lower in PTC patients than that in patients with nodular goiter. We also found that plasma BLACAT1 expression was lower in patients with LNM compared with patients without LNM, whereas there was no difference in BLACAT1 expression among patients with different stages. Similar results were also found in papillary thyroid microcarcinoma. Multivariate analysis indicated that lncRNA BLACAT1 was an independent risk factor of LNM, and the area under the ROC curve of BLACAT1 to distinguish LNM and non-LNM was 0.746. These results suggested that BLACAT1 can be used as a predicting marker of lymph node metastasis. In PTC patients, LNM can be determined by preoperative imaging or intraoperative 

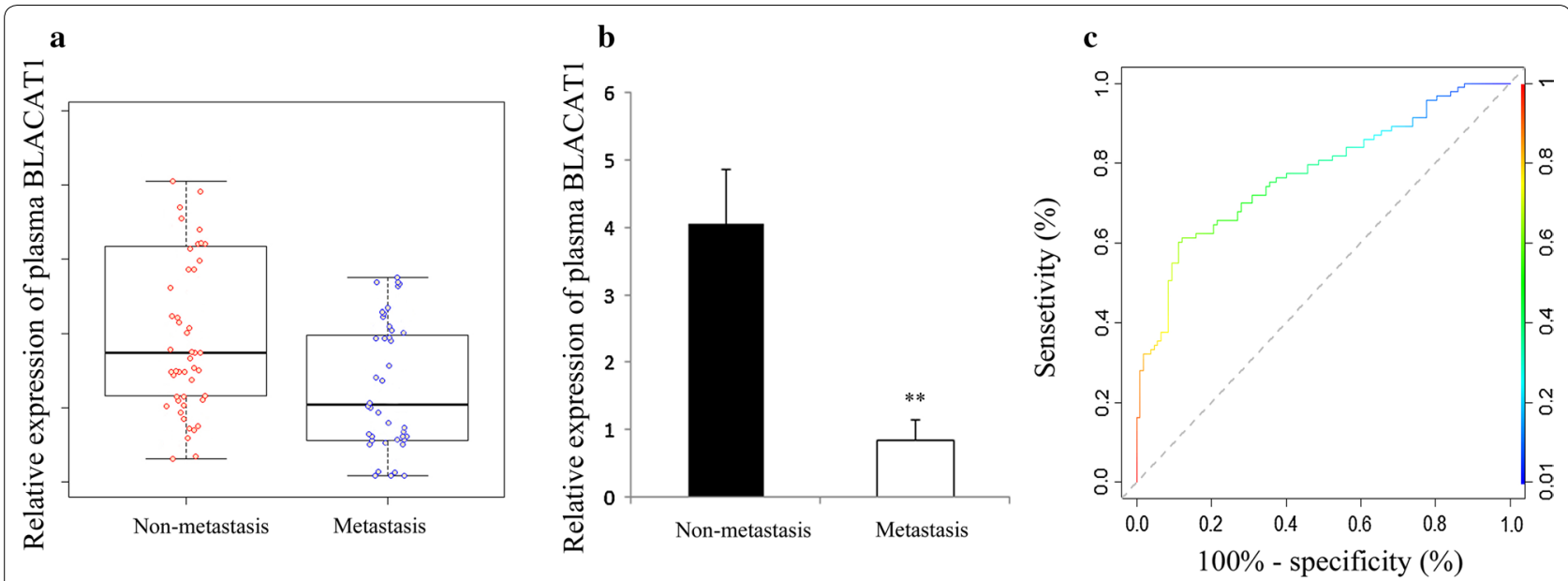

Fig. 2 RT-qRCR and ROC curve analysis of BLACAT1 as a diagnostic marker for lymph node metastasis. Scatter plot (a) and histogram (b) of expression of plasma BLACAT1 in patients with metastasis $(n=41)$ and non-metastasis $(n=46)$; $\mathbf{c}$ ROC curve for evaluating the diagnostic value of BLACAT1 to distinguish PTC patients with metastasis and without metastasis

exploration. LncRNA BLACAT1 in plasma is a potential marker for decision making.

\section{Conclusion}

In conclusion, our results indicated that downregulated plasma BLACAT1 is a potential biomarker for PTC detection, and may predict tumor aggression in patients with PTC.

\section{Authors' contributions}

LSC conceived and designed the experiments. LSC, LG, WT and MJ performed the experiments. WYD collected the clinical data and performed the statistics. LSC wrote the manuscript. All authors read and approved the final manuscript.

\section{Author details}

1 Department of Endocrinology and Breast Surgery, the First Affiliated Hospital of Chongqing Medical University, Chongqing 400043, China. ${ }^{2}$ Department of Breast and Thyroid, Chongqing Traditional Chinese Medicine Hospital, Chongqing 400021, China

\section{Acknowledgements}

We thank Wu JL for critical reading and corrections on the article.

\section{Competing interests}

The authors declare that they have no competing interests.

\section{Availability of data and materials}

The data supporting the conclusions of this paper are included within the manuscript.

\section{Consent for publication}

Not applicable.

Ethics approval and consent to participate

Not applicable.

\section{Funding}

Not applicable.

\section{Publisher's Note}

Springer Nature remains neutral with regard to jurisdictional claims in published maps and institutional affiliations.

Received: 10 February 2018 Accepted: 19 March 2018

Published online: 27 March 2018

\section{References}

1. Becker N, Chernock RD, Nussenbaum B, Lewis JS Jr. Prognostic signifcance of beta-human chorionic gonadotropin and PAX8 expression in anaplastic thyroid carcinoma. Thyroid. 2014;24(2):319-26.

2. Siolek M, Cybulski C, Gasior-Perczak D, Kowalik A, Kozak-Klonowska B, Kowalska A, Chlopek M, KluzniakW, Wokolorczyk D, Palyga I, Walczyk A, Lizis-Kolus K, Sun P. Lubinski J, Narod SA, Gozdz S. CHEK2 mutations and the risk of papillary thyroid cancer. Int J Cancer. 2015;137(3):548-52.

3. Bellevicine C, laccarino A, Malapelle U, Sasso FC, Biondi B, Troncone G. PAX8 is expressed in anaplastic thyroid carcinoma diagnosed by fineneedle aspiration: a study of three cases with histological correlates. Eur J Endocrinol. 2013;169(3):307-11.

4. Wang LY, Roman BR, Migliacci JC, Palmer FL, Tuttle RM, Shaha AR, Shah JP, Patel SG, Ganly I. Cost-effectiveness analysis of papillary thyroid cancer surveillance. Cancer. 2015;121(23):4132-40.

5. McHenry CR, Stulberg JJ. Prophylactic central compartment neck dissection for papillary thyroid cancer. Surg Clin N Am. 2014;94(3):529-40.

6. Wisotzki C, Friese M, Ehresmann J, Derlin T. Esophageal metastasis from papillary thyroid cancer: diagnosis by 1311 SPECT/CT. Clin Nucl Med. 2014:39(1):e73-4.

7. Elisei R, Viola D, Torregrossa L, Giannini R, Romei C, Ugolini C, Molinaro E, Agate L, Biagini A, Lupi C, Valerio L, Materazzi G, Miccoli P. Piaggi P, Pinchera A, Vitti P, Basolo F. The BRAF(V600E) mutation is an independent, poor prognostic factor for the outcome of patients with low-risk intrathyroid papillary thyroid carcinoma: single-institution results from a large cohort study. J Clin Endocrinol Metab. 2012;97(12):4390-8.

8. Xie X, Shi X, Guan H, Guo Q, Fan C, Dong W, Wang G, Li F, Shan Z, Cao L, Teng W. P21-activated kinase 4 involves TSH induced papillary thyroid cancer cell proliferation. Oncotarget. 2017:8(15):24882-91.

9. Kan JY, Wu DC, Yu FJ, Wu CY, Ho YW, Chiu YJ, Jian SF, Hung JY, Wang JY, Kuo PL. Chemokine (C-C Motif) Ligand 5 is Involved in Tumor-Associated Dendritic Cell-Mediated Colon Cancer Progression Through Non-Coding RNA MALAT-1.J Cell Physiol. 2015;230(8):1883-94. 
10. Mao X, Su Z, Mookhtiar AK. Long non-coding RNA: a versatile regulator of the nuclear factor-kappaB signalling circuit. Immunology. 2017;150(4):379-88.

11. Yang P, Chen T, Xu Z, Zhu H, Wang J, He Z. Long noncoding RNA GAPLINC promotes invasion in colorectal cancer by targeting SNAI2 through binding with PSF and NONO. Oncotarget. 2016;7(27):42183-94.

12. Kim D, Lee WK, Jeong S, Seol MY, Kim H, Kim KS, Lee EJ, Lee J, Jo YS. Upregulation of long noncoding RNA LOC100507661 promotes tumor aggressiveness in thyroid cancer. Mol Cell Endocrinol. 2016;431:36-45.

13. Chen X, Dai M, Zhu H, Li J, Huang Z, Liu X, Huang Y, Chen J, Dai S. Evaluation on the diagnostic and prognostic values of long non-coding RNA BLACAT1 in common types of human cancer. Mol Cancer. 2017;16(1):160.

14. McFadden DG, Vernon A, Santiago PM, Martinez-McFaline R, Bhutkar A, Crowley DM, McMahon M, Sadow PM, Jacks T. p53 constrains progression to anaplastic thyroid carcinoma in a Braf-mutant mouse model of papillary thyroid cancer. Proc Natl Acad Sci USA. 2014;111(16):E1600-9.

15. Rothenberg SM, McFadden DG, Palmer EL, Daniels GH, Wirth LJ. Redifferentiation of iodine-refractory BRAF V600E-mutant metastatic papillary thyroid cancer with dabrafenib. Clin Cancer Res. 2015;21(5):1028-35.

16. Vanden Borre P, McFadden DG, Gunda V, Sadow PM, Varmeh S, Bernasconi M, Jacks T, Parangi S. The next generation of orthotopic thyroid cancer models: immunocompetent orthotopic mouse models of BRAF V600E-positive papillary and anaplastic thyroid carcinoma. Thyroid. 2014;24(4):705-14.

17. Conzo G, Mauriello C, Docimo G, Gambardella C, Thomas G, Cavallo F, Tartaglia E, Napolitano S, Varriale R, Rossetti G, Fei L, Santini L. Clinicopathological pattern of lymph node recurrence of papillary thyroid cancer. Implications for surgery. Int J Surg. 2014;12(Suppl 1):S194-7.

18. Anonymous. The Emerging Roles of Long Noncoding RNA ROR (lincRNAROR) and its Possible Mechanisms in Human Cancers.Cell Physiol Biochem. 2016:40(1-2):219-229.
19. Kondo Y, Shinjo K, Katsushima K. Long non-coding RNAs as an epigenetic regulator in human cancers. Cancer Sci. 2017;108(10):1927-33.

20. Yin DD, Zhang EB, You LH, Wang N, Wang LT, Jin FY, Zhu YN, Cao LH, Yuan QX, De W, Tang W. Downregulation of IncRNA TUG1 affects apoptosis and insulin secretion in mouse pancreatic beta cells. Cell Physiol Biochem. 2015;35(5):1892-904.

21. Wang D, Wang D, Wang N, Long Z, Ren X. Long non-coding RNA BANCR promotes endometrial cancer cell proliferation and invasion by regulating MMP2 and MMP1 via ERK/MAPK signaling pathway. Cell Physiol Biochem. 2016;40(3-4):644-56.

22. Ye C, Shen Z, Wang B, Li Y, Li T, Yang Y, Jiang K, Ye Y, Wang S. A novel long non-coding RNA Inc-GNAT1-1 is low expressed in colorectal cancer and acts as a tumor suppressor through regulating RKIP-NF-kappaB-Snail circuit. J Exp Clin Cancer Res. 2016;35(1):187

23. Wang D, Ding L, Wang L, Zhao Y, Sun Z, Karnes RJ, Zhang J, Huang $\mathrm{H}$. LncRNA MALAT1 enhances oncogenic activities of EZH2 in castrationresistant prostate cancer. Oncotarget. 2015;6(38):41045-55.

24. Botti G, Marra L, Malzone MG, Anniciello A, Botti C, Franco R, Cantile M. LnCRNA HOTAIR as prognostic circulating marker and potential therapeutic target in patients with tumor diseases. Curr Drug Targets. 2017;18(1):27-34

25. Huang X, Zhou X, Hu Q, Sun B, Deng M, Qi X, Lu M. Advances in esophageal cancer: a new perspective on pathogenesis associated with long non-coding RNAs. Cancer Lett. 2018;413:94-101.

26. Zhou X, Ye F, Yin C, Zhuang Y, Yue G, Zhang G. The interaction between MiR-141 and IncRNA-H19 in regulating cell proliferation and migration in gastric cancer. Cell Physiol Biochem. 2015;36(4):1440-52.

\section{Submit your next manuscript to BioMed Central and we will help you at every step:}

- We accept pre-submission inquiries

- Our selector tool helps you to find the most relevant journal

- We provide round the clock customer support

- Convenient online submission

- Thorough peer review

- Inclusion in PubMed and all major indexing services

- Maximum visibility for your research

Submit your manuscript at www.biomedcentral.com/submit
() Biomed Central 